\title{
The Inter-American Human Rights System: notable achievements and enduring challenges
}

\section{Par Engstrom}

In the teaching, as well as in the historiography, of international human rights, regional human rights systems, with the partial exception of the European Court of Human Rights, remain marginalised. This is regrettable for a number of reasons; not least because the richness of regional experiences with human rights offers us a more nuanced understanding of the enduring attraction of human rights around the world (as well as a better sense of the diversity and contentious political struggles that characterise them), than that prevailing in the current literature proclaiming the endtimes of human rights (Hopgood 2013; Moyn 2012).

Nowhere can this be seen better than in the region of the Americas, where the Inter-American Human Rights System (IAHRS) emerged to play a vanguard role in the development of the modern international human rights regime. This short piece briefly reviews the current state of the IAHRS, and highlights its key achievements, as well as some of the many challenges it faces. It should be pointed out, from the outset, that any list of achievements and challenges inevitably depends on perspective, the specific yardstick adopted, and, in particular, the understanding of what could be reasonably expected from the IAHRS.

\section{Achievements}

In the interest of brevity, five points serve to illustrate how the IAHRS has emerged as the central human rights reference point in the region of Latin America, in particular.

First, in terms of rule-making, both the Inter-American Commission on Human Rights and the Inter-American Court of Human Rights perform a crucial function in the development of human rights standards. The Court has developed progressive human rights jurisprudence through its rulings. The Commission also serves an important function in this regard through its 
thematic reports and development of policy guidelines, for example, in such diverse areas as freedom of expression, rights of detainees, and land rights. The IAHRS has become increasingly ambitious not only in terms of the types of human rights challenges it deals with, but also in terms of what it demands from states. In particular, the Inter-American Court's evolving policies of reparations now span from monetary compensation to victims, symbolic reparations (e.g. memorials), to demands for state reforms and criminal prosecutions of individual perpetrators.

Second, another important function of the IAHRS concerns monitoring and evaluation of state practices. From its institutional origins as a 'classical' intergovernmental regime, the IAHRS has evolved into an institutionally robust and autonomous system. Its legal and institutional architecture is today dramatically different from the one originally set up in the immediate period following the adoption of the American Declaration of the Rights and Duties of Man in 1948. An independent court and commission are invested with the mandate to respond to individual claims by judging whether domestic legislation, policies and particular actions or omissions violate international state commitments.

Third, the IAHRS has established itself as an important advocacy actor in its own right. The Commission, in particular, has developed a fairly comprehensive set of tools in addition to individual cases that range from public diplomacy in the form of press releases, public hearings, onsite visits, interim measures (precautionary mechanisms), to behind the scenes negotiations with state officials and individual petitioners. The IAHRS also performs a significant indirect advocacy role by providing an important platform for human rights NGOs, some of which have been very adept at integrating the IAHRS into their advocacy strategies in order to bring pressure for change in their domestic political and legal systems.

Fourth, the IAHRS performs important accountability functions; though we should not exaggerate their relative robustness. Various mechanisms have been developed by the IAHRS to hold states accountable for human rights violations: Court rulings, compliance reports, etc. True, these are weak accountability mechanisms in the sense that there are no enforcement mechanisms in place to hold states responsible for implementation. For example, there is no clearly mandated political compliance mechanism, as assumed by the Committee of Ministers in the European system. Still, accountability can operate through various channels, including primarily domestic accountability mechanisms e.g. in the form of mobilisation of public opinion around specific cases, raising awareness through media strategies, and domestic litigation processes.

Finally, the focus on domestic politics highlights the ways in which the IAHRS has become increasingly inserted into domestic policy and legislative debates on specific human rights issues across the region. This signals a gradual move away from a dominant focus on contentious litigation of individual 
cases to attempts to settle cases through friendly settlement procedures. This 'change of paradigm' in human rights activism also reflects the increasing use of individual cases to promote broader government policy changes and institutional changes.

\section{Challenges}

The achievements of the IAHRS are considerable when considered against the often inhospitable regional conditions prevailing throughout the Americas. Yet, these institutional successes contain the seeds of the many challenges facing the IAHRS. Two particularly important challenges stand out, concerning accessibility and 'impact', on the one hand, and the politically contested status of the system, on the other.

First, does the system 'matter' to those mostly in need, however conceived? This is, in part, a question of access and participation. Individuals and groups in the Americas may submit complaints of human rights violations to the Inter-American Commission, and the Commission may refer cases to the InterAmerican Court if the country involved has accepted the Court's jurisdiction. Indeed, individual access to the human rights regime has strengthened over time as the system has evolved into a judicial regime with a procedural focus on the force of legal argumentation and the generation of regional human rights jurisprudence. The system institutionally legitimises and discursively encourages civil society participation, and it formally empowers citizens to bring suit to challenge the domestic activities of their own government. No longer, therefore, a mere quasi-judicial entity with an ill-defined mandate to promote respect for human rights in the region, today's IAHRS offers important opportunities for human rights activists to bring pressure for change in their domestic political systems.

We should not, however, overstate the general accessibility of the IAHRS to individual petitioners. The capacity of actors to access and to mobilise the IAHRS is highly unequal. Successfully accessing the IAHRS requires a high level of legal and technical expertise. In practice, this means that the vast majority of petitions that actually gain traction in the system - i.e. proceed beyond initial submission phase - are advocated by NGOs. Nonetheless, engaging in the process of litigation before the IAHRS involves very lengthy proceedings that imply a significant drain on already limited resources for NGOs that pursue litigation. The process before the System is also highly unpredictable and partial state compliance with IAHRS decisions is often the best outcome petitioners can realistically hope for. Still, the Commission receives an increasing number of petitions, which has led to a significantly increased case-load, and back-log of cases, for the system.

Another aspect to note in this regard is that individuals and groups do not have direct access to the Court. The Commission only has the mandate to bring 
cases to the Court. In practice, this means that Commission lawyers have been delegated the responsibility to act on behalf of individual petitioners. This also often means that professional human rights NGOs bring cases representing individual victims or group of victims. The structure of these dynamics is such that potential problems of representation and legitimacy may arise, with NGOs pursuing interests and objectives that are not necessarily aligned with the needs and interests of individual victims; e.g. devising litigation strategies that may that seek to leverage individual cases to bring about broader policy and legislative changes.

Even more crucial, however, is the limited capacity of the IAHRS. The system is able to process only a small number of the petitions submitted. Given the vast human rights challenges facing contemporary societies in the region, moreover, only a miniscule proportion of the violations committed on a daily basis are presented to the IAHRS. This reality raises, once again, several thorny yet important questions concerning the accessibility of the system, particularly for marginalised and vulnerable individuals and groups in the region, who, arguably, are those most in need of the system's support for the realisation of their human rights.

A second challenge to the system concerns its future, in light of political changes in the region, as well as broader global shifts that may increasingly challenge the international human rights regime. The IAHRS is subject to some very significant legitimacy and authority challenges. From the perspective of the users of the IAHRS, as already highlighted, the system can appear fairly inaccessible. The internal functioning of the system also raises questions concerning its perceived legitimacy and efficacy. For example, one common criticism is that the Commission is not transparent in its selection of what cases to accept. The length of proceedings also undermines claims that justice is rendered even in cases that result in a Court ruling. Doubts are regularly raised concerning the competence, independence, and motivations of individual members of the Commission and the Court.

Moreover, there is significant regional variation with regards to the formal adherence to the system. This is reflected in the uneven adoption of regional human rights instruments by OAS member states. Indeed, one of the contentious issues surrounding the IAHRS is precisely its uneven ratification record. While most Latin American states demonstrate a high degree of formal commitment to the IAHRS, the US, Canada, and most of the English-speaking Caribbean have not ratified the American Convention on Human Rights (1969) and have not accepted the jurisdiction of the Court. In addition, states are regularly questioning the authority of the System; some are withdrawing their diplomatic and financial support. Trinidad and Tobago's withdrawal from the American Convention following its continuing commitment to the death penalty took effect in 1999; Venezuela announced its withdrawal in 2012, and the Constitutional Court of the Dominican Republic ruled in 2014 to 
withdraw from the Inter-American Court's jurisdiction (Engstrom 2015). This raises the problem of having one system seeking to apply general principles of law in a regional context characterised by considerable heterogeneity between, and within, countries.

Indeed, the significant political tensions surrounding the IAHRS in recent years highlight that processes of institutional development are not necessarily progressive, nor unidirectional. True, there may be a basic recognition of certain fundamental human rights principles in the Americas. Beyond this basic normative consensus, however important it may be, recent debates within the OAS concerning the scope and direction of IAHRS reforms suggest that some states question the institutional direction of travel of the IAHRS. Trenchant criticisms in recent years from several member states may suggest that the IAHRS is on the verge of overstretching its institutional mandate. Efforts by states to constrain or rein in the IAHRS may need to be seen, moreover, in the broader context of an uncertain future for the global human rights regime in light of the wider implications of shifting global power balances from which the Americas as a region is not immune. As power shifts globally, as well as regionally in the Americas, competing understandings of sovereignty that emphasise sovereign equality may reassert themselves challenging the demands and expectations of human rights advocates. Indeed, debates within the OAS in the context of the recent IAHRS reform process reflect an enduring and deep disquiet towards external monitoring and sanction of the human rights record of governments. From this perspective, it may be argued that it is precisely the institutional development of the IAHRS, in ways that have escaped the control of states, which has prompted significant pushback by certain groups of states within the OAS.

Without doubt, it is important to recognise the very real limitations of the IAHRS and to be sober about the many challenges the system is facing. Yet, there continue to be reasons to be cautiously optimistic about the future of the IAHRS. Despite its institutional weaknesses, the IAHRS performs many important functions as outlined above. As reflected in steadily increasing petitions to the Commission, the system continues to be turned to by those who have been denied justice at home. The demand from victims and their relatives, and human rights organisations across the region, remains, in other words, robust and growing.

\section{Bibliography}

Engstrom, P. (2015) 'El Sistema Interamericano de Derechos Humanos y las Relaciones Estados-Unidos América Latina’ Foro Internacional, LV(2), pp. 454-502.

Hopgood, S. (2013) The Endtimes of Human Rights (Ithaca, NY: Cornell University Press). 
Moyn, S. (2012) The Last Utopia: Human Rights in History (Cambridge: Harvard University Press). 